\title{
Incentivo à cultura: experiências brasileiras de políticas públicas - interesses da área da Ciência da Informação
}

\author{
Encouragement of culture: Brazilian experiences \\ of public policies - interests in the area \\ of Information Science
}

\author{
Adriana Buarque de HOLANDA' \\ Maria Cristina Guimarães OLIVEIRA² \\ Simone Rosa de OLIVEIRA ${ }^{3}$
}

\section{Resumo}

O artigo objetiva apontar duas experiências de políticas públicas sociais voltadas à questão da informação. A primeira trata de uma ação legislativa do Estado que enfoca o livro e a biblioteca, e a segunda é uma iniciativa da sociedade civil organizada que objetiva minimizar o analfabetismo funcional. Com o intuito de contextualizar o interesse da Ciência da Informação como Ciência Social Aplicada, apresenta-se tal disciplina com os atributos de estimular e orientar ações políticas em prol da distribuição do acesso à informação de forma mais igualitária junto à sociedade.

Palavras-chave: Ciência da Informação. Cultura. Políticas públicas.

\section{Abstract}

The aim of this article is to show two experiences of social policies directed towards the question of information. The first is a legislative action of the State that focuses on the book and the library, and the second is an initiative of organized civil society with the goal of minimizing functional illiteracy. In order to contextualize the interest of Information Science as an Applied Social Science, this discipline is presented with the attributes of stimulating and guiding political actions for the more equitable distribution of access to information more in society.

Keywords: Information Science. Culture. Public politics.

\section{Introdução}

O conceito de política pública deixa evidente o estabelecimento de uma relação com a análise política, como ilustra Pereira (2008, p.90):
Com Aristóteles, na Grécia Antiga, o conceito clássico de política era compreendido como centrado nas atividades do Estado, relacionando-se com a convivência humana coletiva. Através de mecanismos de coerção ou concessão, a

\footnotetext{
1 Analista da Informação, Fundação Joaquim Nabuco. Recife, PE, Brasil.

2 Professora Doutora, Universidade Federal de Pernambuco, Programa de Pós-Graduação em Ciência da Informação. Av. da Arquitetura, s/n., Cidade Universitária, 50740-550, Recife, PE, Brasil. Correspondência para/Correspondence to: M.C.G. OLIVEIRA. E-mail: <macol@uol.com.br>.

3 Assessora de Gestão da Informação, Instituto de Tecnologia de Pernambuco. Recife, PE, Brasil.

Recebido em 21/5/2012, reapresentado em 2/8/2012 e aceito para publicação em 27/8/2012.
} 
política pode apresentar-se mais ou menos democrática, a depender do regime político ao qual pertence. Já nas ditaduras, a manipulação dos direitos coletivos faz-se mais presente que nos regimes abertos: por meio da força, da ameaça, da sedução e do ocultamento, associados ao uso intensivo da sagacidade.

Na condição democrática encontrada em diferentes regimes, a participação popular deve encontrar o apoio do Estado para a realização das necessidades sociais, considerando-se o direito à cidadania política, mesmo que uma série de reivindicações não saia do plano legislativo. A política social, por sua vez, faz parte do conglomerado das políticas públicas, e resgata a relação entre a teoria e a prática política para além dos tradicionais estudos políticos; sendo multidisciplinar, pode abranger outros campos científicos que interferem em questões sociais, a exemplo do serviço social, e pode, a partir tanto de iniciativas privadas, quanto das ações do próprio Estado, ampliar o próprio sentido da política, com o intervencionismo popular.

A incorporação da problemática do desenvolvimento ao cenário da administração local, pública em especial, relaciona-se às reflexões e alternativas para a redução das disparidades regionais, sobretudo as disparidades culturais. Tal postura exige dos municípios o manejo de diferentes tipos de informação, o trabalho em dimensões não convencionais e ainda a reunião de espaços geralmente dispersos e a avaliação da rentabilidade social das inovações públicas.

No transcurso do tempo, a Comissão Econômica para a América Latina e o Caribe (CEPAL) aponta como importante nas formas de gestão a consideração das demandas de cada ambiente físico-territorial e os múltiplos aspectos do urbano associados aos elementos que surgem em seu ambiente econômico e sociocultural, comentam Jordan e Simioni (1998). Dessa forma, esses elementos, vinculam-se aos objetivos do desenvolvimento urbano e estão associados aos aspectos econômicos, sociais e culturais e, por sua vez, também unidos aos processos políticos da tomada de decisão. Nesse caso, o acesso aos serviços e equipamentos urbanos de educação, cultura e informação garante a promoção da integração social e cultural às comunidades envolvidas.

Por sua vez, o acesso aos bens culturais, não apenas materialmente, exige a utilização prévia de recursos para seu entendimento, ou seja, educação e formação apropriada para o entendimento do significado de cada bem cultural, o que representa, na visão de Canclini (2000) a base de uma sociedade democrática e suficientemente organizada.

Pelo exposto, é importante a discussão sobre a informação como recurso de poder, vinculada que está ao desenvolvimento e à capacidade da própria sociedade de gerar e aplicar conhecimentos, a partir do acesso à educação e à informação.

Todos têm o direito ao acesso a informações do próprio interesse particular, coletivo ou geral, já que o desenvolvimento passa pela informação. Diferentes autores, entre eles Araújo (1999), Jambeiro et al. (2007), Lourenço e Freire (2008), vêm apontando a importância da informação para o exercício da cidadania, especialmente a consciência de deveres e direitos relacionados ao acesso e uso de informações de interesse dos cidadãos, a chamada informação social. Nessas condições, há uma demanda explícita por diretrizes e políticas que possibilitem o desenvolvimento de atividades e projetos voltados à gestão e ao acesso amplo e irrestrito a informações, que garantam a democratização de informações.

Sob essa perspectiva, as políticas culturais são muito relevantes, pois funcionam como incentivo à valorização do território local. Compreender a abrangência dessa questão se impõe como condição para a percepção da efetiva ação da política cultural e suas subsequentes ações normativas. Na esperança de garantir a promoção da integração social, mostra-se que a informação tem valor e alcança seu objetivo no momento em que pode ser utilizada pela sociedade como um todo. Especialmente as discussões em torno de políticas culturais permitem que sejam creditados valores tidos como significativos para a divulgação de tentativas locais.

A Ciência da Informação como Ciência Social Aplicada pode ser compreendida como um campo disciplinar que atua junto aos interesses coletivos, promovendo o acesso à informação. Neste caso, só tem sentido falar de um conhecimento como informação quando se estabelece uma relação diante de um pressuposto conhecido e compartilhado com outros. Assim o trabalho informativo contextualiza ou recontextualiza o conhecimento, no qual o valor da informação encontra-se na 
possibilidade prática de aplicar esse conhecimento às necessidades concretas, além de repensar a forma de articulação e o compromisso de todos com a sociedade, defende Oliveira (2008).

Para Nascimento e Marteleto (2004, p.3), "[...] as dimensões históricas, culturais, econômicas, tecnológicas, sociais e políticas são pré-condições para o entendimento da informação" como um fenômeno de ordem cultural. A educação é percebida por Marteleto (1986, p.52) como um fator de desenvolvimento econômico e social, a partir do aumento da renda, da modernização, especialmente da ciência e da tecnologia; e pela construção de uma sociedade mais igualitária. Ocorrendo onde existe cultura, a educação é a materialização da interferência humana no fato social. Educação e comunicação são dispositivos sociais que caminham lado a lado: "[...] para que um processo de comunicação ocorra [...], é necessário que os interlocutores utilizem um código comum e tenham um repertório semelhante de experiências, conhecimentos, informações".

Conforme Braman (1989, p.2), o dilema das abordagens que envolvem a conceituação do termo informação acentua-se quando se trata de políticas de informação. "[...] o argumento sobre como definir informação é crítico porque a definição é central no emergente regime de política de informação". Esse regime, abalizado pelos imperativos das novas tecnologias de informação e comunicação, traduz o entendimento da informação como uma mercadoria, como a percepção de um padrão ou como uma força constitutiva da sociedade: nessa definição está visível o papel ativo da informação ao afetar o contexto em que é aplicada. Continuando, (Braman, 1989, p.7) adianta que:

Fazer qualquer política de informação, quando definida como uma força constitutiva da sociedade é fazer uma decisão de como a sociedade deve ser estruturada - como as classes devem ser distinguidas e como elas devem interagir, o balanço entre os diretos do indivíduo e estes na comunidade.

Dessa forma, políticas públicas sociais não são apenas relacionadas ao Estado: seu sentido é alargado quando se volta à atuação pública "de e para" todos, no que se baseiam certas premissas políticas centradas na universalização dos direitos sociais. Visando concretizar direitos sociais, os serviços sociais, de acordo com Pereira
(2008, p.95) "[...] cumprem o papel de materializar, de fato, as propostas, as ideias, os desenhos de ação, os objetivos e meios especificados pelas políticas públicas". Nesse sentido, as políticas públicas sociais que atuam na efetivação do direito à informação devem referir-se às ações que viabilizem o acesso a todos os instrumentos sociais e suportes comunicacionais que contemplem o acesso à informação como vetor de transformação social.

Também Bourdieu (1998) ao tratar do poder simbólico, coloca o acesso à informação no patamar de algo capaz de dividir a sociedade entre os que possuem mais ou menos informação, fugindo da apresentação das iniquidades geradas pela divisão social baseada apenas na diferença de classes. Trata-se de uma ideia, compartilhada por Marteleto (1986, p.55), que se refere à cultura e à educação: os indivíduos são entendidos como os detentores da cultura erudita ou como defensores da cultura popular, nas quais o folclore e a linguagem popular apresentam-se como conceitos em que certos convencionalismos estão embutidos:

[...] a cultura dominante é nutrida pelo sistema tradicional de conhecimento [...] e influi sobre as massas como forma política externa e logo, como elemento de subordinação a uma hegemonia exterior, que limita o pensamento original das classes populares, e isso de maneira negativa.

Esses instrumentos sociais de acesso à informação podem estar localizados nos "lugares de memória", expressão cunhada por Pierre Nora, ao referir-se aos estoques de informação que pretendem servir à recuperação da informação no futuro, a exemplo das bibliotecas e museus, tendo uma importância fundamental nas políticas de educação, assim como nas de cultura (Nora, 1993). Oliveira e Rodrigues (2009, p.218) ressaltam que "Nas sociedades tradicionais, a memória estava incorporada ao cotidiano [...]. No mundo moderno, ela precisa ser incorporada a lugares socialmente instituídos para ser produzida e reproduzida". Nora (1993, p.7) aponta para os lugares da memória como "[...] uma estratégia criada pelas sociedades contemporâneas para o problema da perda de identidade dos grupos sociais [...]". Tais lugares da memória têm utilidade e dão sentido aos símbolos sociais, sendo compostos por conhecimentos produzidos não intencionalmente, mas que delimitam certas fronteiras socioculturais para que a identidade desses grupos não caia no esquecimento. 
Fortalecendo o pensamento de Pereira (2008), é importante deixar evidente que a política pública pode não significar só ação. Pode ser não ação intencional, isto é, o que o governo escolhe não fazer. Não fazer nada também é uma política, e, através de omissões deliberadas e permeadas por relações de poder, a política pública pode ser manipulada de forma a aumentar ou diminuir a desigualdade no acesso à informação.

Nesse caso, adotando-se as prerrogativas defendidas por Pereira (2008), já mencionadas, o conceito de política pública presente neste trabalho, refere-se à política voltada à compreensão das contradições presentes entre a teoria e a práxis do Estado, aquela política que rompe com o enfoque hierárquico, linear e funcionalista normalmente presente nesse artifício e como tal, defendemos a adoção de uma noção de bem-estar aplicada às políticas sociais com ênfase nas ações do governo que privilegiam tais práticas.

Especificamente, adota-se uma observação apenas ilustrativa para comparar um exemplo de política governamental em andamento com alguns resultados positivos, consequência das diretrizes do Plano Nacional do Livro e Leitura (PNLL), cuja lei inclui o tema livro e leitura nas políticas culturais; por sua vez esses planos vão compor o Plano Nacional de Cultura, aprovado em 2012, com uma projeção para a área de cultura que se estende até 2020 .

Através de revisão literária e conceitual como método de procedimento da pesquisa exploratória, busca-se proporcionar uma visão aproximativa do assunto. Nessa proposta de estudo, foi possível entender as diferenças entre as propostas de ação social do Estado versus as propostas da sociedade civil organizada, cujo Plano Nacional de Cultura resultado de inúmeras propostas da sociedade civil busca atender vários segmentos envolvidos com essa área. O que vai ao encontro da opinião de Pereira (2008, p.98):" [...] as políticas públicas [...] resultaram de novas relações entre Estado e Sociedade, em que os conceitos de justiça social e equidade tornaram-se menos abstratos". Dessa forma, acredita-se que o exercício da cidadania é possível através de relações em que o poder simbólico é distribuído de forma mais igualitária.

Os direitos já conquistados pela sociedade devem ser fáceis de acessar, por serem públicos e indivisíveis, condicionando a legislação à ação social, e a teoria à prática política. Tais direitos estão relacionados às políticas públicas e são os chamados direitos sociais, pois englobam princípios de liberdade, igualdade e fraternidade, e consideram as diferenças de classe, de raça e de etnia, de gênero, entre outras, e proporcionam o exercício igualitário da cidadania, através dos atributos da paz, da autodeterminação dos povos, do meio ambiental saudável e da preservação do patrimônio cultural da sociedade. Nesse sentido:

[...] as políticas públicas, além de se preocuparem com a provisão de bens materiais [...] têm de contribuir para a efetiva concretização do direito do ser humano à autonomia, à informação, à convivência familiar e comunitária saudável, ao desenvolvimento intelectual, às oportunidades de participação e usufruto do progresso (Pereira, 2008, p.103).

Não é objetivo do presente trabalho reforçar uma política pública social que vise à assistência social plena, pois, em muitas vezes, de forma mais ou menos sutil, tais políticas podem se apresentar como formas de assistencialismo.

\section{Políticas públicas sociais do Estado para o direito à informação}

O Ministério da Cultura (MinC) vem articulando com o Ministério da Educação (MEC) o Plano Nacional do Livro e Leitura (PNLL), composto de centenas de ações, projetos, programas e políticas governamentais e da sociedade civil. Entre as ações do MinC, na área de livro e leitura destacam-se a implantação e modernização de bibliotecas, a implantação de Pontos de Leitura, as bolsas para escritores e os prêmios literários, realizados pela Fundação Biblioteca Nacional (FBN) e pela Coordenadoria Geral de Livro e Leitura (CGLL) - vinculada ao Gabinete do Ministro (Brasil, 2006, 2012).

O Plano Nacional do Livro e Leitura é um conjunto de ações continuadas, além de eventos empreendidos pelo Estado de maneira geral, nas esferas federal, estadual e municipal que envolve também a sociedade civil (setor privado e terceiro setor) para promover o livro, a leitura, a literatura e as bibliotecas no Brasil. Na realidade, o PNLL é resultado de várias ações em andamento desde o ano de 2003, como, por exemplo: Lei do Livro no 10.753/2003; Programa Fome do Livro de 2004; e Ano Ibero-Americano de Leitura, Ano Viva Leitura de 2005. 
Referindo-se ao PNLL, assim como aos planos de outras políticas federais, observa-se que, quase sempre, esses planos têm por princípio a possibilidade de se estenderem aos estados e municípios. Nesse caso, os interessados elaboram seus próprios planos e recebem apoio do Governo Federal, que tem como proposta em 2012 revisar a Lei de Incentivo à Cultura, também chamada Lei Rouanet. Já através do PNLL foram previstas instalações de uma biblioteca em cada município, além da criação de Pontos de Leitura - um acervo básico de livros de literatura infanto-juvenil, um computador, almofadas -, no entanto sem pagamento previsto para os mediadores de leitura. Esse é o caso, por exemplo, do primeiro Ponto de Leitura implantado no Brasil, denominado Biblioteca do Bode, no Pina, Recife (PE).

Apesar da relevância das ações em andamento no território nacional, cujos municípios mais distantes puderam contar com a implantação de bibliotecas comunitárias e pontos de leitura, muito ainda precisa ser realizado, inclusive educar a população para zelar pelos espaços culturais e ainda pela manutenção desses locais. Em algumas regiões do País, além de se levar mais educação, tornam-se necessárias mais práticas, ações culturais diversas para efetivamente se considerar uma proposta de mudança cultural na grande maioria da população. Exposição contundente sobre essa realidade encontra-se na pesquisa "Retratos da Leitura no Brasil", realizada nos anos 2007-2008, conforme dados do Censo Demográfico do Instituto Brasileiro de Geografia e Estatística (2010).

Considerando as metas do Plano Nacional de Cultura de 2012, é possível afirmar que existem processos de mudança sobre a adoção de políticas públicas, em curso. Em sua maioria, ainda contam com pouca participação da sociedade civil organizada, porque só agora é possível se tratar de participação coletiva com todas as letras. $\mathrm{Na}$ realidade, esses processos se estendem aos próprios governos locais, os quais, de maneira geral, classificam políticas do livro, de bibliotecas, de música e de teatro como questões menores em cada gestão especialmente porque são atitudes influenciadas pelos políticos cujas práticas às vezes oportunizam o acesso àqueles já estruturados e de nomes já plenamente estabelecidos no cenário cultural. Hoje, é possível registrar alguns avanços, principalmente em relação às mudanças de concepção, de estruturas governamentais, de mentalidades, como evidenciado nas últimas ações do Ministério da Cultura (2003-2010).

\section{Políticas públicas sociais da sociedade civil organizada para o direito à informação}

O Instituto Brasil Leitor (IBL) é uma organização não governamental que atua em várias regiões brasileiras no desenvolvimento de serviços de informação voltados ao atendimento da população em geral, especialmente as classes consideradas populares. Com incentivo financeiro da iniciativa privada nacional e estrangeira, o IBL promove a intimidade dos sujeitos com diversos tipos de materiais informativos e instrucionais, como livros, revistas, jornais, vídeos e demais audiovisuais, através da instituição de bibliotecas populares em logradouros e em parques industriais (as bibliotecas funcionais), além das bibliotecas voltadas à primeira infância, situadas no interior de empresas de diversas naturezas. Sendo, muitas vezes, a extensão do trabalho de incentivo à leitura iniciada no ambiente escolar, as bibliotecas do IBL possibilitam o empréstimo domiciliar dos documentos de seus acervos, além de desenvolver atividades culturais em parceria com outras instituições, públicas e privadas.

Essa instituição também ampliou uma pesquisa de mapeamento do nível de leitura, com uma sinopse do ensino do Brasil, através da análise do censo escolar e do parque gráfico nacional em congruência à conjuntura econômica brasileira, além dos investimentos do setor publicitário nessa área. A minimização do índice brasileiro de analfabetismo funcional é a principal meta institucional. Segundo a denominação da própria instituição, analfabetismo funcional pode ser entendido como "[...] a falta de aptidão adequada para a leitura e a escrita em uma sociedade em que o entendimento e uso da informação traduzem nível e qualidade de vida" (Instituto Brasil Leitor, [2012?], online). Nesse sentido, a falta de domínio da prosa escrita, o baixo entendimento dos termos de um documento ou a pouca manipulação de dados quantitativos podem levar a uma situação em que o pleno exercício da cidadania está sujeito à incapacidade de decodificação e compreensão dos dados informacionais. É importante mencionar que o censo do Instituto Brasileiro de Geografia e Estatística (IBGE) de 2009 revela que a 
taxa de analfabetismo entre homens com idade acima de 14 anos de idade foi de 9,8\% e a das mulheres, para a mesma faixa etária, foi menor, de 9,6\%, em oposição aos dados desse mesmo censo realizado há dez anos, no qual o analfabetismo tinha um gênero e uma idade: concentrava-se em mulheres de mais de 50 anos. Entre as regiões, o Nordeste é uma evidência preocupante, com uma taxa de analfabetismo de 18,7\% em 2009, sendo a maior do País, seguida pela região Norte, com taxa de 10,6\%, Centro-Oeste (8,0\%), Sudeste (5,7\%) e Sul (5,5\%).

Vale não perder de vista que a cultura está incluída como fator estratégico de desenvolvimento social e econômico, a partir de um viés simbólico no qual se encontra explícita a demanda pela produção e organização de informações. Nas palavras de Ziviani (2008), o acompanhamento e a avaliação dessas políticas culturais nos obrigam à reflexão sobre os limites e potencialidades desses levantamentos de dados, com informações específicas para subsidiar atividades de produção cultural. Esse é o aspecto mais importante a ser destacado neste trabalho, pois, com o fortalecimento da democracia, a cultura de mecenato vem sendo substituída por um processo de direito que pressupõe a universalização de oportunidades mediadas pela informação disponibilizada e acessível a todos os interessados.

Caberia destacar que essa significação das experiências coletivas e de seus princípios mais relevantes defendidos neste trabalho como direcionamento às ações políticas aponta para a necessidade de fortalecimento de políticas culturais, especialmente as locais, como uma promessa de educação para o desenvolvimento e do sentimento de pertencimento a uma coletividade. Nesse caso, parte-se do entendimento das manifestações culturais como um direito de todos os cidadãos.

\section{Considerações Finais}

Busca-se evidenciar neste trabalho a relevância do campo de conhecimento chamado informação social. Na realidade, a própria exposição do texto deixa evidente a consistência e a consolidação que os estudos da informação social vêm conquistando no âmbito das Ciências Sociais, especialmente a Ciência da Informação. Isto se deve à amplitude da inserção e do uso da informação pela sociedade contemporânea em todos os níveis, inclusive na gestão pública, ou seja, do ponto de vista da sociedade, é crescente a produção e o uso de informações como parte de um processo social e cultural.

Aqui fica confirmado que na busca por promover a integração social e cultural, o saber tem valor e alcança seu objetivo no momento em que pode ser utilizado pela sociedade como um todo, ajudando comunidades a conhecer sua história e a entender a razão de seus principais problemas sociais. No nível político, essa questão passa pela democratização da informação, permite associar (e qualificar) informação social à geração, recepção e transmissão de informações pautadas nas práticas informacionais existentes num campo social onde está contida a cultura.

\section{Referências}

ARAUJO, E.A. Informação, sociedade e cidadania: gestão da informação no contexto de organizações não governamentais (ONGs) brasileiras. Ciência da Informação, v.29, n.2, p.155-167, 1999.

BOURDIEU, P. O poder simbólico. 2.ed. Rio de Janeiro: Bertrand Brasil, 1998.

BRAMAN, S. Defining information: an approach for policymakers. Telecommunications Policy, v.13, n.3, p.233-242, 1989.

BRASIL. Ministério da Cultura. Plano nacional do livro e da leitura. Brasília: MinC, 2006.

BRASIL. Ministério da Cultura. As metas do plano nacional de cultura. Brasília: MinC, 2012. Disponível em: <www.cultura. gov.br/politicas-culturais>. Acesso: maio 2012.

CANCLINI, N.G. Culturas híbridas. São Paulo: Edusp, 2000.

INSTITUTO BRASIL LEITOR. Projeto ler e saber. [2012?]. Disponível em: <http://www.brasilleitor.org.br>. Acesso em: 4 abr. 2012

INSTITUTO BRASILEIRO DE GEOGRAFIA E ESTATÍSTICA. Censos demográficos. Rio de Janeiro: IBGE, 2010. Disponível em: <http://www.ibge.gov.br/home>. Acesso em: 4 ago. 2012.

JAMBEIRO, O.; BORGES, J.; SOBREIRA, R. Políticas e gestão de informação pública: o caso da Prefeitura de Salvador. Informação \& Sociedade, v.17, n.2, p.109-118, 2007.

JORDÁN, R.; SIMIONI, D. (Org.). Ciudades intermedias de América Latina y el Caribe: propuestas para la gestión urbana. Santiago de Chile: CEPAL, 1998. Disponible: <http://www.eclac.cl/ dmaah/gucif/libropdf.htm>. Acceso: 21 jul. 2012. 
LOURENÇO, B.A.; FREIRE, G.H. Construindo um mapa das políticas públicas para gestão e acesso à informação em comunidades carentes. Biblionline, v.4, n.1/2, 2008.

MARTELETO, R.M. Informação e educação: a distribuição da informação na sociedade. Tempo Brasileiro, v.86, n.7-8, p.46-60, 1986

NASCIMENTO, D.M.; MARTELETO, R.M. A informação construída nos meandros da teoria social de Pierre Bourdieu. Revista DataGramaZero, v.5, n.5, 2004. Disponível em: <www dgz.org./out.04/índex>. Acesso em: maio 2012.

NORA, P. Entre memória e história: a problemática dos lugares. Projeto História, n.10, p.7, 1993.

OLIVEIRA, E.B.; RODRIGUES, G.M. As concepções da memória na ciência da informação no Brasil: estudo preliminar sobre a ocorrência do tema na produção científica. Ponto de Acesso, v.3, n.3, p.216-239, 2009. Disponível em: <http://www. portalseer.ufba.br/index.php/revistaici/article/view/3613/ 2745>. Acesso em: 25 jul. 2012.

OLIVEIRA, M.C.O. O uso social da informação na rede de desenvolvimento de Santo Amaro. In: ENCONTRO NACIONAL DE PESQUISA EM CIÊNCIA DA INFORMAÇÃO, 9., 2008, São Paulo. Anais Eletrônicos.... São Paulo: ENANCIB, 2008. Disponível em: <http://enancib.ibict.br/índex>. Acesso em: 5 jul. 2009.

PEREIRA, P.A. Discussões conceituais e direito à cidadania. In: PEREIRA, P.A. Política social no capitalismo: tendências contemporâneas. São Paulo: Cortez, 2008. p.87-108.

ZIVIANI, P. A consolidação dos indicadores culturais no Brasil: uma abordagem informacional. 2008. Dissertação (Mestrado em Ciência da Informação) - Escola de Ciência da Informação, Universidade Federal de Minas Gerais, Belo Horizonte, 2008. 
